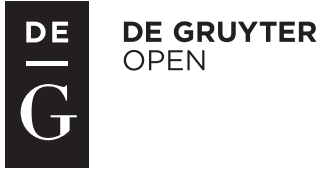

DOI: 10.2478/topling-2014-0007

\title{
Fractal metaphor LIFE IS A STORY in biographical narrative
}

\author{
Yakiv Bystrov \\ Taras Shevchenko National University of Kyiv, Ukraine
}

\begin{abstract}
The paper applies an interdisciplinary perspective to a fictional text showing that fractals as mathematical models are a powerful tool for conceptualizing life experience in biographical narratives. The multilevel construction of Chatterton by Peter Ackroyd is explored on the basis of fractal metaphor theory. This research focuses on the LIFE IS A STORY conceptual fractal metaphor which is built up on analogical mappings, mental space connections, and blends. The fractal model of metaphor in biographical narrative, which is assigned to the formula LIFE IS A STORY $f(1)+f(2)+f(3)+\ldots+f(n)$, contains the mental space of the intentional source domain story, which provides a way to structure the understanding of the limiting target domain of the concept life. Fractal metaphors aim at making the conceptual metaphor flexible and dynamic, renewing its ability of self-development and self-perfection, transforming itself into one of the means of changeable conceptualization of reality.
\end{abstract}

\section{Keywords}

Biographical narrative, conceptual metaphor, cross-domain correspondences, blend, fractal metaphor theory, self-similarity, recursion.

\section{Introduction}

In biography it is common to conceptualize one's life in terms of a story. Zoltán Kövecses, Metaphor (2002)

This paper looks at the underlying conceptualization of life in our understanding of narrative discourse. This conceptualization manifests itself in cognitive metaphors as fractals from different domains of physical experience where the underlying 'image schema' of source in terms of a story is of paramount importance. It must be activated and used in particular contexts to permit a rich conceptualization of life experience. Ultimately, the aim of the paper is to show that fractal models are a powerful tool for conceptualizing life experience in biographical narratives.

The methodological use of metaphor as a means of analysis in areas other than linguistics is a relatively recent phenomenon. Since language is the vehicle for expressing the conceptual system which we use in thinking and acting, it is the main source of information about the structure of that system. From the publication of Lakoff and Johnson's book Metaphors We Live By (1980), the study of conceptual metaphor has undoubtedly been one of the major topics in the field of cognitive linguistics research. The theory of conceptual metaphor has certainly stirred up the world of linguistics, and its applications have been extended to numerous areas such as discourse analysis, pragmatics and contrastive analysis.

In this research, I argue that there exists a bipartite relationship among cognitive linguistics via a conceptual metaphor, and chaos theory via a fractal model, which separates this analysis from earlier studies using a cognitive approach in linguistics and literature. This research thus moves towards a new interpretation of biographical narrative. Furthermore, exploring the metaphors used in a particular discourse or aspect of a discourse is a particularly fruitful 
route into a deeper understanding of such a phenomenon as biographical narrative in fiction. The latter could be defined as a story or its interpretation relating key facts or events with a person's (narrator's) life from the perspective of another person (narrator). In this analysis of biographical narratives from Peter Ackroyd's Chatterton (1987), we focus on the fractal nature of conceptual metaphor. We consider it appropriate at this point to define the fractal metaphor LIFE IS A STORY.

\section{Theoretical background}

\subsection{Conceptual Metaphor Theory}

The focus on metaphor has undoubtedly been enhanced by the 'discovery' of preconceptual or cognitive metaphor in the work of the leading exponents of cognitive linguistics, prominently Lakoff and Johnson (1980), Lakoff and Turner (1989), and Gibbs (1994). They share the common assumption, which goes back to classical times, that humans categorize their experience into general concepts so as to make sense of the astounding variety of the world. But they contest the traditional idea that our categorized concepts are an objective representation of reality and therefore primary, which means that all imaginative conceptualizations are derivative and to be labelled figurative, poetic or metaphorical. In the cognitivist view, metaphors can be expressed in language precisely because human thought processes are essentially metaphorical.

Recent development in conceptual metaphor theory is connected with the analysis of individual texts and genres and the works of the researchers who continue to identify mappings at a more detailed level, using the theory of conceptual blending, which has proved to be a productive approach for this purpose (e.g. Fauconnier and Turner, 1998; Fludernik, 2010; Górska, 2010; Bruhn, 2011 ).

In the present paper, my focus is on conceptual metaphors which are really more like "conceptual frames that enclose sets of metaphorical expressions that are consistent with the framing conceptualisation" (Turner, 1997 , p.24) with an outlook of further possible applications of blending theory.

Kövecses's Metaphor: A Practical Introduction (2002) is a very useful textbook on the methodology of the cognitive linguistic study of metaphor. In his book, Kövesces differentiates between linguistic and non-linguistic metaphors where the latter reveals the nonlinguistic realization of conceptual metaphors in literature and where such a literary subgenre as biography is based on a given metaphor. Moreover, "this practice is based on the LIFE IS A STORY conceptual metaphor. When the telling of one's life is presented as if it were a story, it gains its structure from the metaphor LIFE IS A STORY" (Kövecses, 2002, p.65).

Moving beyond the idea that metaphor indicates simple comparisons, we examine the parts of metaphor: the source and target domains. When words are used in metaphorical senses, one field or domain of reference is mapped onto or carried over another on the basis of some perceived similarity between the two fields. With the view of this research, in which we are going to prove the dynamic nature of the conceptual metaphor, it became possible to differentiate between its intentional counterpart aimed at the infinite number of self-similar structures, and its limiting counterpart which is responsible for the boundary referent in question. Thus, the limiting starting point may be called the 'target' domain, while the comparative concept, or the intentional one, is called the 'source' domain.

Though we may no longer see them as metaphorical, there are numerous common expressions which show how metaphors structure our everyday concepts. An abstract concept can now be defined simply as a 'mapping' of one semantic domain onto the other. This model suggests that abstract concepts are formed systematically through such mappings and that specific metaphors are traces to the target and source domains (Danesi, 2008, p.99).

Lakoff's LIFE IS A JOURNEY (1980) is a prototypical example of the preconceptual structure emerging from pervasive everyday experience. Every time we move anywhere, there is a place we start from, a place we end up at, places in between, and a direction. This basic image-schema serves for the mapping system of conceptual metaphors themselves, i.e. the target domain is conceptualized in terms of the source domain. The metaphor entails interpretation because the source interprets the target. So in the LIFE IS A JOURNEY, the source domain, journey provides the basis for the target domain, life.

The pervasiveness of the journey metaphor is reflected in its mapping onto the process of life itself. We go through life from birth to death. After a period of difficulty, we carry 
on with our lives. In their More than Cool Reason, Lakoff and Turner refer to the pervasiveness of the journey metaphor as follows (Lakoff and Turner, 1989, pp.60-61):

"Our understanding of life as a journey uses our knowledge about journeys. All journeys involve travellers, paths travelled, places where we start, and places where we have been. Some journeys are purposeful and have destinations that we set out for, while others may involve wandering without any destination in mind, consciously or more likely unconsciously, a correspondence between a traveller and person living life, the road travelled and the 'course' of a lifetime, a starting point and a time of birth, and so on."

A recurring leitmotif of the series of biographical narratives confirms the idea that the metaphor, which may be labelled LIFE IS A STORY, goes beyond the conventional metaphor LIFE IS A JOURNEY. Moreover, adopting conceptual blending theory (Fauconnier and Turner, 1998), I will suggest that we are dealing here with a complex integration network that includes: setting up mental spaces, mapping elements from one space to another, and blending these spaces. In this approach, elements (or counterparts) refer to objects in the world indirectly as objects in our mental representations. As we understand the metaphor through indirect mental representations, two mental spaces with relevant information can be built up, first about a story, and then about life. Figure 1 represents these two mental spaces set up to represent LIFE IS A STORY.

The mental space of the concept story is a source domain because it provides a way to structure the understanding of the target domain of the concept life. The representation of story includes the elements of fictional characters/narrators, a starting point, (re)interpretations, and an ending point which structure the mental space of our specific knowledge about stories. Another container, with the characteristic elements of a person living the life, birth, life experiences, and death, structures the mental space of our general knowledge about life.

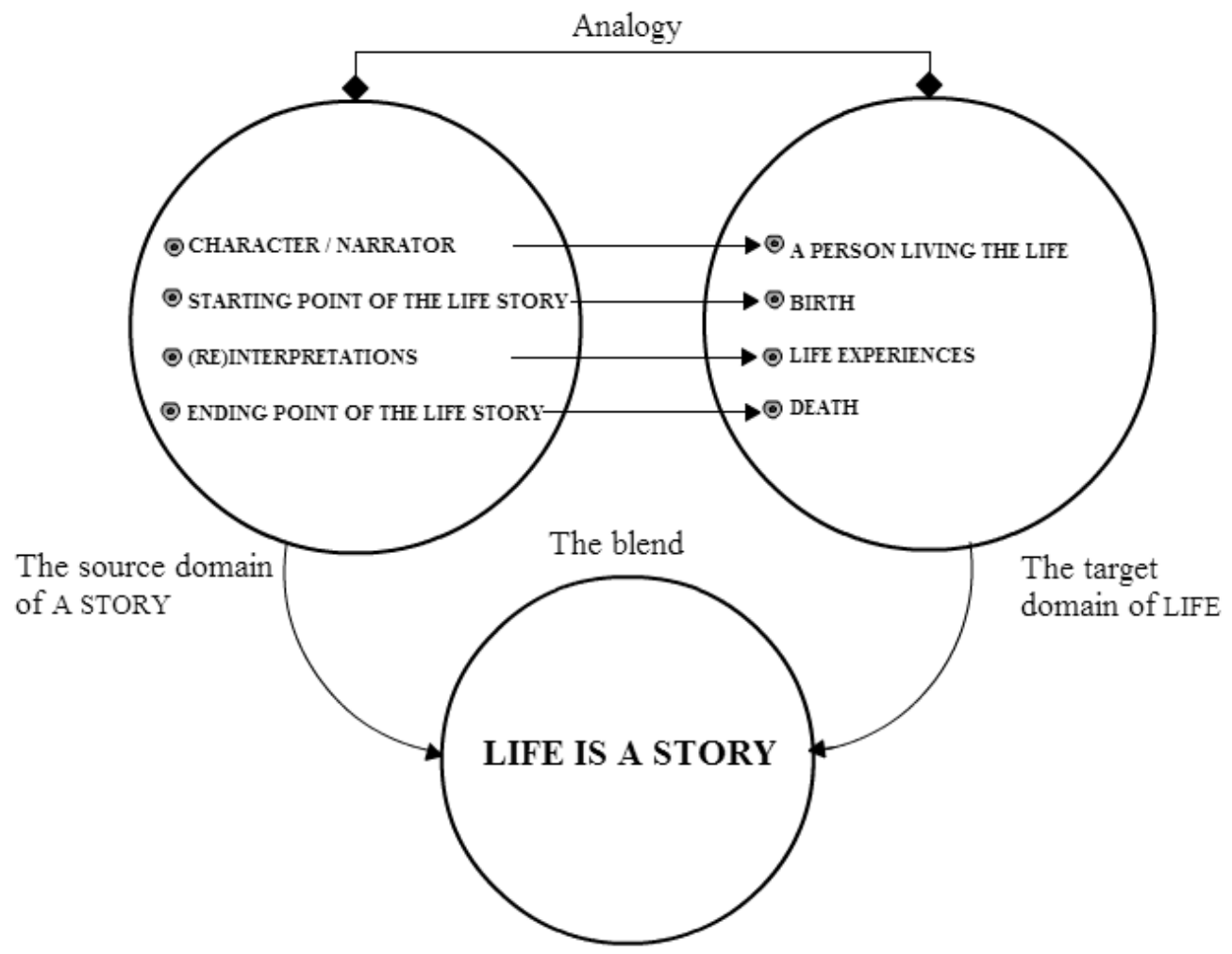

Figure 1. LIFE IS A STORY: cross-domain correspondences

Later, after setting up spaces and after mapping elements from the source to the target, we need to form a new mental space to store the results of the previous cognitive activities into the blend. Thus, this new space is based on analogical features and contains the following information:

- The person living the life is a fictional character or narrator in the narrative. 
- His birth is a starting point in the life story.

- His life experiences are the

(re)interpretation in the narrative.

- His death is the ending point of the life story.

The next stage of analysis is to locate all the instances of the conceptual metaphor as they appear in metaphorical propositions in which the concept life is made explicit in each of the elements of the mapping structure. At this point, I detect conceptual metaphor through certain metaphorical propositions, i.e. the metaphor visible at the surface-level of phrases, e.g. 'give myself as good a Lineage as any Gentleman in Bristol', 'a monk of the fifteenth century, Thomas Rowley', or in the sentences, e.g. "he would no longer be the poet who died young and glorious, but a middle-aged hack who continued a sordid trade with his partner" (C 221). The real/fictional character/narrator's death may also be conceived metaphorically by the character/narrator himself (e.g. the luxury of death).

Similarly, analogical mappings may be observed between life experiences and their interpretations in the narrative: 'The final effect [of that painting] it has upon the world can never be anticipated or measured or arranged.' Meredith was looking across at the turbulent surface of the water. 'That is what I mean by its reality' - a door was opened and closed somewhere - 'It can only be experienced. It cannot be spoken of.' $\mathrm{He}$ paused, as if listening to the sound of the hurrying footsteps. 'And yet the words for it still haunt us, pluck at us, fret us' (C 162).

Therefore, to understand life as a story is to have in mind, consciously or more likely unconsciously, a correspondence and a blending of the elements in the two mental spaces.

\subsection{Fractal Metaphor Theory}

As far as we are concerned, in literary criticism there are references connecting the chaos and bifurcation theory to the fractal structure of the text in prose and poetry, where these citations to fractality have appeared from a qualitative point of view with the aim of formalizing the narrative rules of a text, and where even fractal geometry as a mathematical approach is employed for textual analysis. The textual perspective of fractal structures has often merged with the literary perspective (e.g. Eftekhari, 2006; Finan, 2012; Mikkelsen,
2002; Sassón-Henry, 2006; Wenaus, 2011), psycholinguistic perspective (e.g. Butner, Pasupathi and Vallejos, 2008), and even computer games perspective (e.g. Coleman, 2009).

On a more general level, the considerations exposed above constitute the motivation for both cognitive linguistics and literary studies to use the fractal structures similar to those used in the chaos and bifurcation theory. The theoretical concepts, including iteration, self-similarity, strange attractors, dissipative structures, and fractals, and a fractal-type analysis could provide a particularly effective interpretive framework for being applied in literary narratives. Additionally, it becomes evident that a fractal model being a selfsimilar, integral and split structure at one time, participates in the formation of infinite number of conceptual domains in a fictional text. As Werth claimed in the 1990s, "I would like to consider conceptualization itself as being structured fractally. The brain itself looks like a fractal object" (Werth, 1999, p.337) (my emphases).

Through the widely spread chaos theory as a guiding aesthetic principle in Chatterton, a new conceptual structure and a device namely fractal metaphor - illuminates Ackroyd's novel. Similarly, it governs a unique approach to biographical narrative explicating the quality of self-similarity thus effecting "a kind of reconciliation of part and whole" and "a concern with the connection of parts to whole" (Finan, 2012, pp.68-69) within conceptualized fractal fragments.

With the publication of Benoît Mandelbrot's Fractal Geometry of Nature (1983) the notion of fractality has been employed in different branches of science and also in textual analysis in particular. According to his theory, fractals may have various characteristic sizes, fractal shapes or structures are self-similar and independent of size or scale, and they are the result of an iterative or recursive construction. In his research, Wenaus, for instance, pointed out: "Fractals are of particular value as metaphors for postmodern structures". In this account, "the fractal quality of self-similarity on all scales of iteration is of interest for examining narrative structures that shift in and out of various ontological levels", in biographical narratives in particular (Wenaus, 2011, p.159).

The fractal approach that can best accommodate the multiple meanings of the text is arguably a poststructuralist one, which is an assembly of varied fragments 
with internal structures rather than with explicit linear narrative trajectories, and those which can be repeated, played or skipped, attended to in a different order, etc. These polyfurcated fragments in biographical narrative result in the fractal structure that allows for multiple, nonhierarchical prototype and exit points in the historical originality of Chatterton's real life and death and its possible representation. Consequently, Chatterton's biography could be extended through the novel's strategy of giving real biographical information and its juxtaposition with the fictive narrative.

Both the narrative structure and the preface of Chatterton display recursive patterns of self-reference and self-similarity throughout the novel. Ackroyd prefaces the novel with a brief summary of Chatterton's life and career, emphasizing his dream of poetic fame. Chatterton's dream can be realized by recursion in terms of self-similar fractal fragments that "may be conceptualized as a feedback where the length of the loop curve is infinite while the structure itself only occupies a finite amount of space" (Wenaus, 2011, p.159).

Thus, the preface of the novel contains four fragments from the novel, introducing the protagonists and forecasting the themes that are further extended in the form of fractal self-similar structures to make up a multilayered "truthful" biographical portrait of Thomas Chatterton. Each time a narrator tells a story (or paints a picture), this story becomes the input for the next story. The looping process which is based on the reproduction of stories may result in an infinite set of stories.

Framing empirical facts in some abstract metaphorical schemes make it possible to regulate the sections of the novel thus transforming them into a functional unit of cognition. As a rule, a metaphor is "tied" to real prototypes and representations, and becomes insensitive to constant changes of its factual information. Thus, metaphor mappings not only supplement and guide contemporary literary criticism but also conceptualize the segments that stand out in the act of artistic creation through "the capacity of metaphor to represent the phenomena that are of specific cognitive and narrative value" (Glotova, 2013, p.62).

The fractal metaphors are assigned to make the metaphor flexible and dynamic, renewing its ability of self-development and self-perfection, transforming itself into one of the means of changeable conceptualization of reality. Thus, these metaphors may appear or disappear, and may either may be transformed or improved. Moreover, intentional (or ones approaching to infinity) and limited sides of cognition can be combined in fractal metaphors as in any mathematical models (or geometrical figures).

In what follows, the domains of fractal metaphor are not modified within the utterance but multiplied outside the utterance. Specifically, Chatterton is scrutinized in terms of multiple authenticity and authorship:

(1) 'I know. That is why I have come to see you, Tom.' Then he said in a softer voice, 'You may live well without Rowley, if you choose to. I have no doubt that there are other Authors within you' (C 90), and also through a plot concerned with postmodernist "reality" or "fakery", and with the Chatterton as a historical (fictional) fake:

(2) The real world is just a succession of interpretations. Everything which is written down immediately becomes a kind of fiction (C 32).

The multilayered portrait of Chatterton as a starting point and the multilayered painting at the end of the novel serve as a basis for fractal metaphors in the web of self-similar intertexts and citations that summon up a whole history of interpretations.

\section{Findings and discussion}

In this section, biographical narratives in Chatterton (1987), by Peter Ackroyd, will be discussed. The novel draws on the tragic career of the eponymous 18th-century poet and plagiarist, tracing his "life journey" and the echoes of his death on writers and artists starting from the Romantic period and ending with the postmodern period. In turn, the idea of history writing and imitationwith-distortion of history is extended and emphasized throughout the narration of Chatterton. As Sassón-Henry (2006) claims, "the act of reading becomes an act of making meaning in a multilayered maze. As the reader processes different readings, initial chaos and disorder become simultaneously important elements for understanding each individual narrative. Thus, the reading process resembles one of assemblage, whereby the reader tries to piece together how the different narrative threads supplement each other." 
Ackroyd's exploring life writing in the form of palimpsest dissolves the boundary between historical fact and imagined fact, between the real historical figure and the invented one. Ackroyd made up his own multilayered and fictitious portrait of Thomas Chatterton (1752-1770) as one of the various interpretations of Chatterton made by three narrators: Peter Ackroyd, the author, Henry Wallis, the artist, and finally, Charles Wychwood, the poet. One can find the "real" Chatterton, who appears as a character in his own right in the preface of the novel, the Chatterton invented by the author; the middle-aged Chatterton of a fake portrait, the Chatterton, Henry Wallis's painting; and a modern variation of Chatterton in Charles Wychwood who "encounters" the ghost of Chatterton at the end of chapter 4 . Charles resorts to spurious manuscripts and fictitious details; in so doing, he also adds another layer to Chatterton's biographical portrait.

Thus, the very myth which Chatterton invented by himself about his life and death has been revived in possible transformations and self-similarities made by other biographers. This suggestion can be proved by the fractal structure of the postmodern novel that yields self-similar portraits of Thomas Chatterton at a time: "There are so many different layers" (C 158). Moreover, Ackroyd sets up a dialogic interplay between three different historical periods which can be divided into the following fractal narratives:

Story ${ }_{1}$ is about Thomas Chatterton's own brief and rather obscure life (1752-1770).

Story $_{2}$ is set around the year 1856, Henry Wallis completed his portrait of a dead Chatterton lying in his garret, with the young poet George Meredith posing as a model.

Story $_{3}$ is set in the 20th century and centres on the discovery by a poor poet, Charles Wychwood, of a second portrait, a fake representation of Chatterton in his fifties.

In all three fractal narratives, the imageschematic structure of the intentional source domain, i.e. A STORY is transferred onto the limiting target domain, i.e. LIFE. The allusion of a living past is woven with the contemporary scene through Ackroyd's movement between historical fact and historical fiction, between questions of authenticity and questions of forgery. Here, all three stories link fact and supposition, certainty and speculation, real or imagined events by likeness and not by chronology. All three principal fictional figures,
Chatterton (story, who is telling his own life story, and both Meredith (story ${ }_{2}$ ) and Charles (story $\left._{3}\right)_{\text {who }}$ are reinterpreting Chatterton's biography, tend to spiral infinitely, despite being contained in a finite space.

Each of the three self-similar interpretations of the multilayered biographical portrait of Thomas Chatterton influence the dynamics of the fractal model of metaphor which is assigned to the formula $1+2+3+\ldots+(n)$, consisting of a numerical series of fractal stories. In what follows, the system (biographical narrative) should take into account its fluctuations, i.e. interpretations and reinterpretations of life experiences. Thus, the element $f$ is introduced in the formula of fractal metaphor which is as follows: LIFE IS A STORY $f(1)+f(2)+f(3)+$ $\ldots+f(n)$, where the intentional source domain tends to spiral infinitely. In story ${ }_{3}$, for example, initially irritated by the discrepancies and contradictions in the biographies of Chatterton, Charles Wychwood soon begins to write his own interpretation of Chatterton's memoirs. He immerses himself in Chatterton's mirrored fractal vision as if possessed by his spirit: All at once he saw the entire pattern of Chatterton's life, and with redoubled pressure he wrote it down with his empty pen (C 127).

From the LIFE IS A STORY conception first introduced in Kövecses (2002), it is but a short step to see metaphorical manifestations of a fictional character by using recursion. Reinventing the past, Chatterton was also reinventing himself twice: first, by describing himself as "so I, Thomas Chatterton, at the age of Twelve, began my own Great Ledger of the Past. My first task was to give myself as good a Lineage as any Gentleman in Bristol..." (C 85); and second, by representing himself as "a monk of the fifteenth century, Thomas Rowley; I dressed him in Raggs, I made him Blind and then I made him Sing" (C 87).

Similarly, in terms of death, Chatterton is consigned to die repeatedly at different points of time, both in the 19th and 20th centuries. His death is given in comic textual form through the repetition of the phrase the last time five times, always resulted from recursion: "At that instant of recognition he smiled: nothing was really lost and yet this was the last time he would ever see them, the last time, the last time, the last time, the last time" (C 131). On the other hand, Charles Wychwood suddenly announced, "He didn't die. I'm serious. Thomas Chatterton 
didn't die" (C 94). In the same way, Chatterton's death is conceptualized by articulated fractal self-similar structures at different points of time, the first time as tragedy, and the second as comedy.

The LIFE IS A STORY confirms its status as fractal metaphor by combining several narrative levels, each one being conceptualized and involved in the manifestations of fictional reinventions of Chatterton, the recreations of his life and the legends about him which are "intimately related within an explicit context of false representations" (Gibson and Wolfreys, 2000, p.129).

For George Meredith, "There is nothing more real than words. They are reality" (C 122). He claims that, "the invention is always more real" than empirical reality, just as the monk Rowley, whom Chatterton created "out of thin air" (the so called self-interpretation) has "more life in him than any medieval priest who actually existed". "But," he adds, "Chatterton did not create an individual simply. He invented an entire period and made its imagination his own: no one had properly understood the medieval world until Chatterton summoned it into existence. The poet does not merely recreate or describe the world. He actually creates it" (C 122). For Charles Wychwood, "anything became possible. If there were no truths, everything was true" (C 157).

Ultimately, such multiple figuring turns upon the understanding that Chatterton is only knowable as an invention of literary and cultural history which seeks to make him real. As Philip, a librarian and Charles's friend, says about Chatterton's manuscripts: "None of it seemed very real, but I suppose that's the trouble with history. It's the one thing we have to make up for ourselves" (C 174).

\section{Conclusion}

Metaphor is a pervasive process in language, yet we believe that writers have special talents in the creation and use of metaphor. The writer uses metaphors to make a guess about a suspected inner connection among things. "Metaphors are slices of truth; they are evidence of the human ability to see the universe as a coherent organism" (Danesi,

\section{References}

ACKROYD, P., 1987. Chatterton. [S. I.]: Penguin Books.

BRUHN, M.J., 2011. Harmonious madness: The poetics of analogy at the limits of blending theory. Poetics Today, vol. 32, no. 6, pp. 619-662.
2008 , p.114). When a metaphor is accepted as fact, it enters human life, taking on an independent conceptual existence in the real world, and thus it can suggest ways to bring about changes in and to the world.

This study was focused on the idea of fractal analysis as an interdisciplinary approach and a new standpoint on metaphor in a fictional text and designed to introduce the fractal paradigm into the theory of metaphor. The fractal model of metaphor provides a new interpretation of the fictional text that is based on a constant process of selfsimilarity. I have selected excerpts from Chatterton by Peter Ackroyd to illustrate that author and narrators of the novel share similar models of the world, the models which are represented through fractal metaphor. The existence of cross-domain correspondences between LIFE and A STORY supports the idea of regarding this fractal metaphor as a dynamically evolving integration network comprising mental spaces, multiple correspondences and blends. As in conceptual metaphor the image-schematic structure of the intentional source domain is transferred onto the limiting target domain. However, in the fractal model, the image-schematic structure of the intentional source (i.e. story) is not pre-existent but is actively constructed and created by the human mind.

Fractal analysis together with the procedure of reiteration was chosen as a method with the intention of finding out certain linguistic conditions under which biographical narratives can be read through and filled with fractal models. In general terms, the main linguistic characteristics of fractal metaphor in biographical narratives are as follows: three fragmented stories analysed above like geometric fractals are mapping onto the referent "life"; and, consequently, a number of repeated, rotated or recycled phrases, and possible interpretations of life experience which result in the fractals of authenticity, parody, distortion, and plagiarism are all imposed on the target domain LIFE. 
BUTNER, J., PASUPATHI, M. and VALLEJOS, V., 2008. When the facts just don't add up: The fractal nature of conversational stories. Social Cognition, vol. 26, no. 6, pp. 670-699.

COLEMAN, R., 2009. Fractal analysis of stealthy pathfinding aesthetics. International Journal of Computer Games Technology, vol. 2009. [Accessed September 2014] Available at: http://dx.doi.org/10.1155/2009/670459

DANESI, M., 2008. Of cigarettes, high heels, and other interesting things: An introduction to semiotics. 2nd ed. London: Palgrave Macmillan.

EFTEKHARI, A., 2006. Fractal geometry of texts: An initial application to the works of Shakespeare. Journal of Quantitative Linguistics, vol. 13, no. 2-3, pp. 177-193.

FAUCONNIER, G. and TURNER, M., 1998. Conceptual integration networks. Cognitive Science. vol. 22, no. 2, pp. 133-187.

FINAN, T.E., 2012. The "Lords of Life": Fractals, recursivity, and "experience". Philosophy and Rhetoric, vol. 45, no. 1, pp. 65-88.

FLUDERNIK, M., 2010. Narrative and metaphor. In: D. Mclntyre and B. Busse, eds. Language and style. In honour of Mick Short. London: Palgrave Macmillan, pp. 347-363.

GIBBS, R.W., 1994. The poetics of mind. Figurative thought, language, and understanding.

Cambridge: Cambridge University Press.

GIBSON, J. and WOLFREYS, J., 2000. Peter Ackroyd. The Ludic and Labyrinthine Text. London: Macmillan Press Ltd.

GLOTOVA, E., 2013. Metaphor and the political identity of a writer (on the basis of Elizabeth Gaskell's Mary Barton). Topics in Linguistics, no. 12, pp. 56-64.

GÓRSKA, E., 2010. LIFE IS MUSIC. A case study of creative metaphorical thought. English Text Construction, vol. 3, no. 2, pp. 275-293.

KÖVECSES, Z., 2002. Metaphor: A practical introduction. New York: Oxford University Press. LAKOFF, G. and JOHNSON, M., 1980. Metaphors we live by. Chicago and London: The University of Chicago Press.

LAKOFF, G. and TURNER, M., 1989. More than cool reason: A field guide to poetic metaphor. Chicago : Chicago University Press.

MANDELBROT, B., 1983. The fractal geometry of nature. New York: W. H. Freeman.

MIKKELSEN, N., 2002. Diamonds within diamonds within diamonds: Ethnic literature and the fractal aesthetic. Melus, vol. 27, no. 2, pp. 95-116.

SASSÓN-HENRY, P., 2006. Chaos theory, hypertext, and reading Borges and Moulthrop.

Comparative Literature and Culture, no. 8.1. [Accessed April 2014]

Available at: http://dx.doi.org/10.7771/1481-4374.1289

TURNER, J., 1997-8. Turns of phrase and routes to learning: The journey metaphor in educational culture. Intercultural Communication Studies, no. VII, pp. 23-35.

WENAUS, A., 2011 . Fractal narrative, paraspace, and strange loops: The paradox of escape in Jeff Noon's Vurt. Science Fiction Studies, vol. 38, no. 1, pp. 155-174.

WERTH, P., 1999. Text worlds: Representing conceptual space in discourse. London: Longman.

\author{
Author's address and contact details \\ Yakiv Bystrov \\ Taras Shevchenko National University of Kyiv \\ 37 Pivdennyi Blvd., apt. 26, \\ Ivano-Frankivsk 76010 \\ Ukraine \\ Phone: +38067704 6841 \\ E-mail: ybystrov@ukr.net
}

